\title{
O MENEIO AGOSTINIANO DAS CATEGORIAS ARISTOTÉLICAS NAS CONFISSÕES
}

\author{
Cristiane Negreiros Abbud Ayoub \\ Universidade Federal do ABC
}

RESUMO: Nas Confissões de Agostinho, é possível considerar três apreciações diferentes quanto às categorias de Aristóteles: (1) no contexto das artes liberais, (2) no maniqueísmo e (3) ao modo agostiniano. Identificá-las serve à defesa de um argumento, trabalhado por nós ao longo de diversos artigos e capítulos, em prol da relevância de Agostinho na fortuna da história da recepção das Categorias e, consequentemente, da dialética.

Palavras-chave: Agostinho, Confissões, categorias, Aristóteles, maniqueísmo.

\begin{abstract}
In the Confessions of Augustine, it is possible to consider three different appraisals of Aristotle's categories: (1) in the context of the liberal arts, (2) in Manichaeism and (3) in the Augustinian way. Identifying them accomplishes to defend a larger debate, on which we have been working throughout several articles and chapters, in favor of Augustine's relevance in the history of the reception of the Categories and, consequently, dialectics.
\end{abstract}

Keywords: Augustine, Confessions, categories, Aristotle, Manichaeism. 


\section{Introdução}

A recepção da filosofia aristotélica em Agostinho recebeu pouca atenção dos estudiosos, e essa atitude parece coerente com as poucas menções a Aristóteles na extensa obra agostiniana. No entanto, pensamos ser cabível defender um lugar para Agostinho na história da recepção das categorias aristotélicas e na apreciação do valor da dialética, a arte liberal que, na época de Agostinho, era diretamente associada às categorias. Ademais, tal lugar lhe era atribuído ainda em vida, quando um de seus oponentes mais potentes o apelidou de "Aristóteles catarginense", 1 ou quando um outro oponente, um gramático de nome Crescônio, acusou-o de "homem dialético". ${ }^{2}$ Sabemos que se trata de uma empresa pretensiosa e, por isso, temos a trabalhado por etapas. ${ }^{3}$

O estudo que aqui apresentamos concentra-se nas Confissões e evita abordar as outras obras de Agostinho que tecem referências às categorias aristotélicas. ${ }^{4}$ Ademais, não temos a pretensão de analisar esse tema extensivamente nas Confissões, mas apenas na medida em que tenhamos os elementos necessários para sustentar que, nas Confissões, Agostinho expõe pelo menos três modos de lidar com as categorias aristotélicas. Primeiramente, veremos que, ao narrar seu primeiro estudo das Categorias, Agostinho retrata como essa obra integrava o currículo dos estudos das artes liberais, gozando de certo prestígio, na época em que Agostinho teve seu contato (inusitado) com o texto. A segunda abordagem mostra como esse estudo deu a Agostinho razões suficientes para defender e persistir no maniqueísmo. Enfim, o terceiro enfoque propõe outra apreciação em relação às categorias, e antecipa atenuadamente aquilo que se tornará a apropriação genuinamente agostiniana das categorias, ou seja, muito

\footnotetext{
1 audiamus ergo quid parias, aristoteles poenorum (JULIANO DE ECLANO apud AGOSTIHO, c. Iul. imp., III, 199).

${ }^{2}$ hominem dialecticum (Cresc., I, 13, 16).

${ }^{3}$ Outras etapas que defendem a importância da recepção agostinianas das categorias e da dialética foram publicadas em um capítulo (cf. AYOUB, 2013), e em um artigo, que em breve será publicado na revista Analytica (cf. AYOUB, 2019, no prelo).

${ }^{4}$ Agostinho menciona as categorias aristotélicas em: Sobre a dialética, Confissões, Sobre a Trindade e Contra Juliano, obra inacabada. Segundo Olivier du Roy, há evidências de que influenciaram também o De immortalitate animae (DU ROY, 1966, p. 178, n. 2).
} 
embora encontre alguns desenvolvimentos nas Confissões, ainda não se oferece com a clareza, a sistematicidade e o labor que serão característicos dos livros V e VI do Sobre a Trindade.

Certamente, tratando-se de Agostinho, cabe notar que a mudança em relação a alguns aspectos de seu pensamento traduz um traço característico de sua filosofia, e, ao rever suas concepções sobre a realidade, sobre Deus e sobre o alcance da razão e da linguagem humanas, também retrabalhou sua interpretação das categorias, as quais tematizam a ontologia, o conhecimento da realidade e os usos da linguagem que permitem discernir a verdade da falsidade. Essa alteração fica evidente pela avaliação que o próprio Agostinho tece de seu primeiro contato com as categorias. ${ }^{5}$

\section{O contexto do ensino das Dez Categorias, segundo as Confissões}

O fato de que Agostinho tenha lido o texto das Dez categorias é indisputável. ${ }^{6} \mathrm{O}$ primeiro contato do autor com as categorias encontra-se documentado nas Confissões, e deveu-se à obra pertencer ao currículo dos estudos em retórica.

\footnotetext{
${ }^{5} \mathrm{O}$ modo de Agostinho discutir as categorias no Sobre a Trindade deve-se também a outros fatores como a associação corrente na época entre a dialética (e seu uso das categorias) e o combate eunomiano em relação ao dogma da Trindade. Os exemplos e argumentos utilizados por Agostinho (a exemplo daqueles referentes à terminologia ingenitus) comprovam essa colocação. No Sobre a Trindade, do livro V em diante, Agostinho exemplifica o que seria a sua leitura (a mais adequada) das categorias aristotélicas no contexto da defesa do dogma trinitário, revertendo o desprezo que a dialética historicamente vinha recebendo da ortodoxia cristã, por ter sido associada aos diversos arianismos. Em outros termos, Agostinho resgata a dialética de uma associação imediata com os arianismos, e volta a empregá-la como instrumento útil ao discernimento entre verdade e falsidade. O histórico da apreciação das categorias aristotélicas no contexto cristão é examinado e documentado por de Ghellinck, no artigo Quelques appréciations de la dialectique et d'aristote durant les conflits trinitaires du IVe siècle (DE GHELLINCK. J, 1930).
}

${ }^{6}$ Quanto a qual versão Agostinho leu das categorias, não há unanimidade entre os pesquisadores. Reproduzimos as informações oferecidas por James O'Donnel em seu comentário ao Livro V das Confissões: "How Augustine encountered this famous text is a puzzle. In the Aristotelian order (cat. 4.1b2 2a4, top. 1.9.103b20-23), the

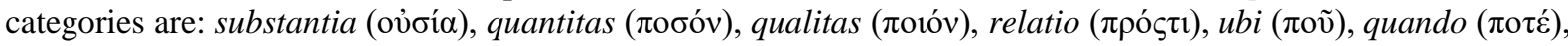

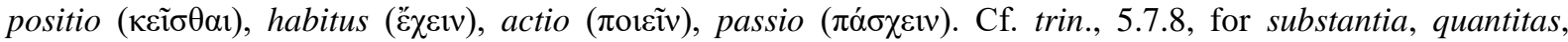
qualitas, relatio, situs, habitus, quando, ubi, facere, pati. The Aristotelian order is reproduced in pseudoAugustine categoriae decem (144.17-19 Minio-Paluello) and in Cassiodorus (inst. 2.10 - with some idiosyncratic variations). But there is another tradition, in Pseudo-Archytas, Mart. Cap. 4.363f, Boethius (in Porph. isag. 1 and 2.1.4) and Chalcidius (in Tim. 305 [307.3-6 Waszink]), according to which quality is the first accident of substance, as here; see I. P. Sheldon-Williams, ed., Johannes Scottus Periphyseon Liber I (Dublin, 1968), 232n98. On the evidence of the order, therefore, Augustine is in the tradition from Porphyry and 
As Dez Categorias, de acordo com as Confissões, foram apresentadas ao jovem Agostinho aos 20 anos de idade, como um conhecimento superior e de tamanho prestígio que estudá-lo parecia uma iniciação, conforme lemos neste texto:

[...] o texto aristotélico que chamam de "Dez categorias" - a cujo nome, quando meu mestre de retórica cartaginense o citava com a boca crepitante de empáfia, era como se eu ingressasse titubeante em algo grande e divino. (conf., IV,16, 28). ${ }^{7}$

Tal reverência traduz um contexto específico e em relação ao qual Peter Brown, em sua biografia sobre Agostinho, observa:

Vinha ocorrendo um ressurgimento dos estudos aristotélicos em Roma, num círculo de aristocratas cultos supervisionados por um erudito professor de grego. A intelectualidade de uma cidade provinciana como Cartago havia-se contentado em falar dessa obra de Aristóteles como algo de "sublime e divino" (BROWN, 2015, p. $60)$.

Uma vez apresentado às Dez Categorias, qual foi a reação de Agostinho e como ele as interpretou inicialmente?

Chalcidius (and leading to Boethius): fully neo-Platonic (and for that matter Porphyrian more than Plotinian: C. Evangeliou, Aristotle's Categories and Porphyry [Leiden, 1988]). For a contrary view, see Minio-Paluello's edition of the cat. dec. in Aristoteles Latinus 1.1-5 (Bruges-Paris, 1961), 129-75, with preface there 1xxvii-xcvi; and Minio-Paluello, CQ 39 (1945), 63-74. Against Minio-Paluello (and Marrou, followed by (...) [E. Tréhorel and G. Boissou in Bibliothèque Augustinienne, Paris, 1962)] and with P. Hadot, Marius Victorinus (Paris, 1971), 187-8, we should doubt Cassiodorus' claim that Victorinus made a translation. Another order, close to the one given here, is in Quintilian (3.6.23): essentia, qualitas, quantitas, ad aliquid, ubi, quando, facere, pati, habere, keisthai (positio). Minio-P., art. cit. 65, says that Varro must have been the first translator, and that no other is known until 350, hence Quint. must/may depend on him or the Greek text or some doxographic source. That Varro may stand in this tradition requires us to pause long enough to remember the other revivals of his name and lore in Augustine's lifetime: Augustine himself quotes him extensively (see Hagendahl for details), and Martianus Capella imitates him in more ways than one" (O'DONNELL, 2018). Cabe apenas notar que, posteriormente, Minio Palluelo reconsiderou seu posicionamento favorável a Agostinho ter lido a versão latina de Vitorino, e defendeu que isso seria pouco verossímil.

${ }^{7}$ [...] et quid mihi proderat, quod annos natus ferme uiginti, cum in manus meas uenissent aristotelica quaedam, quas appellant decem categorias (quarum nomine, cum eas rhetor carthaginiensis, magister meus, buccis typho crepantibus commemoraret et alii qui docti habebantur, tamquam in nescio quid magnum et diuinum suspensus inhiabam) (conf., IV,16, 28). As traduções em português seguem a de Lorenzo Mammì (2017, p. 111). As referências às Confissões apresentam o título da obra abreviado (conf.), seguido de números referentes ao livro (em algarismos romanos), capítulo e parágrafo do texto (ambos em algarismos arábicos). 


\section{Agostinho e seu primeiro estudo das Categorias: ruptura didática?}

As Dez categorias eram consideradas uma obra de difícil entendimento, cujo ensino envolvia mestres eruditos que, além de conhecê-la, deveriam didatizar seu conteúdo com, por exemplo, tabelas e discussões. No entanto, na contramão dessa metodologia, Agostinho estudou-as sozinho devido à sua inteligência ímpar. Tendo abdicado de mestres e de esquemas, Agostinho rompeu com os métodos tradicionais de ensino ${ }^{8}$ o que é reportado no seguinte texto:

E de que me valeu, quando tinha cerca de vinte anos, que caísse em minhas mãos [...] e que o lesse sozinho e o entendesse? E quando conferi com pessoas que diziam tê-lo compreendido a duras penas graças a mestres muito eruditos que o explicavam não só falando, mas também desenhando figuras na areia, elas não me puderam dizer nada mais do que eu mesmo, lendo o livro sozinho, já descobrira; e parecia-me que as "Categorias" falavam com clareza das substâncias (por exemplo, "homem"), do que está nelas (como a figura do homem); sua qualidade e estatura (quantos pés mede), a relação (de quem ele é irmão) e onde ele se encontra, quando nasceu, se está de pé ou sentado, calçado ou armado; se faz ou sofre algo; e todas as coisas inumeráveis, de que forneci alguns exemplos, que se encontram nesses nove gêneros ou no próprio gênero de substância (conf., IV, 16, 28). ${ }^{9}$

Quanto a essa passagem das Confissões, Peter Brown enfatiza que Agostinho, na época desse estudo, manifestava um desejo de compreender tudo racionalmente. O mesmo ímpeto também o levaria a aderir e defender o maniqueísmo, que prometia explicar racionalmente a

\footnotetext{
${ }^{8}$ Segundo James O'Donnel, "Agostinho foi essencialmente autodidata", referindo-se a Mandouze: "Ni la culture universitaire, ni plus tard la culture ecclésiastique ne devaient réussir à tuer en lui ce penchant pour les tranquilles audaces de l'autodidacte" (MANDOUZE, 1968, p. 466 apud O'DONNELL, 1992, nota ao trecho 4.16.28). Agostinho afirma: "Entendi a arte de falar e discutir, as figuras extensas, a música e os números sem grande dificuldade e sem um homem que me ensinasse, tu sabes, Senhor meu Deus, porque tanto a rapidez em entender quanto a acuidade em discernir são tuas dádivas. [...] De fato, só percebia que aquelas artes eram muito difíceis de entender, mesmo por alunos aplicados e inteligentes, quando tentava explicá-las e havia apenas um, o mais proficiente entre eles, que conseguia acompanhar sem demora minha explicação" [quidquid de arte loquendi et disserendi, quid quid de dimensionibus figurarum et de musicis et de numeris sine magna difficultate nullo hominum tradente intellexi, scis tu, domine deus meus, quia et celeritas intellegendi et dispiciendi acumen donum tuum est [...] non enim sentiebam illas artes etiam ab studiosis et ingeniosis difficillime intellegi, nisi cum eis eadem conabar exponere et erat ille excellentissimus in eis, qui me exponentem non tardius sequeretur]" (conf. IV, 16, 30; MAMMI, 2017, p. 113).

${ }^{9}$ et quid mihi proderat, quod annos natus ferme uiginti, cum in manus meas uenissent aristotelica quaedam, quas appellant decem categorias [...] legi eas solus et intellexi? quas cum contulissem cum eis, qui se dicebant uix eas magistris eruditissimis non loquentibus i tan tum, sed multa in puluere depingentibus intellexisse, nihil inde aliud mihi dicere potuerunt, quam ego solus apud me ipsum legens cognoueram; et satis aperte mihi uidebantur loquentes de substantiis, sicuti est homo, et quae in illis essent, sicuti est figura hominis, qualis sit et statura, quot pedum sit, et cognatio, cuius frater sit, aut ubi sit constitutus aut quando natus, aut stet aut sedeat, aut calciatus uel armatus sit aut ali quid faciat aut patiatur aliquid, et quaecumque in his nouem generibus, quorum exempli gratia quaedam posui, uel in ipso substantiae genere innumerabilia reperiuntu (conf., IV, 16, 28; MAMMİ, 2017, pp. 111-112 ).
} 
presença do mal no mundo. Tratava-se, portanto, de uma dupla emancipação de cunho racional: quer por se distanciar dos moldes convencionais de ensino, quer por romper com a tradição religiosa do Império, cujas crenças recusavam a racionalidade. Esse racionalismo é sugerido por Peter Brown:

[...] dos 20 anos em diante, Agostinho foi um professor dedicado, um austero devoto da "Sabedoria", ansioso por aumentar seus poderes de filósofo. Assim, sua "emancipação" religiosa da religião tradicional, quando ele se tornou maniqueísta, coincidiu exatamente com uma emancipação intelectual dos mais velhos e de seus superiores na universidade de Cartago, daqueles professores pretensiosos que ele secretamente desprezava. Para assombro de seus colegas, ele dominou sozinho um livro de lógica aristotélica, o chamado Dez Categorias. [...] somente o jovem Agostinho aceitou o desafio de estudá-la por conta própria. Assim, não chega a surpreender que tenha adotado uma religião que afirmava descartar toda e qualquer crença que ameaçasse a independência de seu cérebro sumamente ativo (BROWN, 2015, pp. 59-60, grifo nosso).

A nosso ver, é preciso dar mais ênfase a essa observação de Peter Brown, pois tanto a emancipação religiosa, quanto a didática apresentam como solo comum uma emancipação racional principal, especificamente em relação aos discursos de autoridade. Contudo, embora o maniqueísmo prometesse explicar a grande questão de Agostinho (sobre a coexistência entre o mal observado no mundo e um Deus criador sumamente bom), na verdade, para decepção de Agostinho, os maniqueus ofereciam apenas narrativas fantasiosas.

Seja como for, o estudo das categorias e a adesão ao maniqueísmo coincidem com tal impulso racional, mas como se deu a relação entre as categorias e o favorecimento da adesão ao maniqueísmo? A resposta é que elas proporcionavam a compreensão da realidade mediante discursos racionais e coerentes com o mundo "materializado" apregoado pelos maniqueus, além de evitar muitas sortes de equívocos.

A teoria aristotélica da predicação mostrava-se hábil para predicar o Deus maniqueu, ponderado com um ser estendido pelo espaço corporal. ${ }^{10} \mathrm{O}$ início do Livro VII das Confissões não permite duvidar desse ponto:

\footnotetext{
${ }^{10}$ O Comentário ao Gênesis contra os maniqueus, escrito por Agostinho em 388-389, analisa diversas críticas maniqueístas aos católicos. Nesse tratado, em grande parte, Agostinho as refuta argumentando que provêm de uma interpretação infantil das passagens do Gênesis, baseada no sentido mais imediato e aparente dos termos, a saber, associados ao que é "corporal".
} 
[...] na juventude, [...] não podendo conceber substâncias senão como aquelas que nossos olhos costumam ver. Não te concebia, Deus, na figura de um corpo humano, desde que começara a estudar um pouco de filosofia; [...] mas não me ocorria outra maneira de te conceber. [...] [Eu] era obrigado a conceber, se não a forma de um corpo humano, todavia algo corporal que ocupasse extensões espaciais, infundido no mundo ou difundido por espaços infinitos fora do mundo, ainda que, por ser incorruptível, inviolável e imutável, o colocasse acima do que é corruptível, violável e mutável. [...] Assim concebia inclusive a ti [...] como algo grande que ocupava espaços infinitos em toda parte e penetrava a inteira massa do mundo e a excedia por todos os lados até a imensidão sem limite, de maneira a conter a terra, conter o céu, conter tudo, e de maneira que tudo tivesse seus limites em ti, mas tu não tivesses limites $^{11}$ (conf., VII, 1, 1-2). ${ }^{12}$

${ }^{11} \mathrm{O}$ texto prossegue com a exposição da concepção agostiniana de Deus, quando ainda em coerência com o maniqueísmo: "Mas como a luz do sol não encontra resistência no corpo do ar - aquele ar que está acima da terra - e pode atravessá-lo penetrando-o sem o quebrar ou cortar, mas enchendo-o por completo; assim julgava que houvesse permeabilidade para ti não apenas no céu, no ar e no mar, mas até no corpo da terra, e que tua presença pudesse penetrar em todas as coisas, das maiores às menores, e tu fosses interno a elas como um sopro oculto, e externo enquanto regedor de tudo o que criaste. Supunha assim, porque não conseguia conceber de outra forma; mas era falso. Com efeito, dessa maneira, uma porção maior de terra conteria uma tua parte maior, e uma menor, menor; e todas estariam cheias de ti, de modo que o corpo de um elefante conteria mais do que o corpo de um passarinho, por ser maior e ocupar um espaço maior; e assim tuas partes, divididas em pedaços, estariam presentes, as maiores, nas partes maiores do mundo; as menores, nas mais reduzidas [...] E fiz de tua criatura uma única grande massa, diferenciada segundo os gêneros de corpos, tanto aqueles que realmente são corpos, quanto aqueles que eu imaginava em lugar dos espíritos, e a fiz grande não quanto era, porque não podia sabê-lo, mas quanto quis, porém finita por todos os lados; quanto a ti, Deus, imaginei que a abrangesses e penetrasses, mas que fosses infinito por todos os lados, como um mar que ocupasse todos os lugares da imensidão, um único mar infinito em que houvesse uma esponja grande quanto se possa imaginar, porém finita, e essa esponja fosse preenchida em toda parte pelo mar imenso; assim julgava que tua criatura finita fosse preenchida pelo infinito" [sicut autem luci solis non obsisteret aeris corpus, aeris huius, qui supra terram est, quominus per eum traiceretur penetrans eum non dirrumpendo aut concidendo, sed implendo eum totum, sic tibi putabam non solum caeli et aeris et maris sed etiam terrae corpus peruium et ex omnibus maximis minimisque partibus penetrabile ad capiendam praesentiam tuam, occulta inspiratione intrinsecus et extrinsecus administrantem omnia, quae creasti. ita suspicabar, quia cogitare aliud non poteram; nam falsum erat. illo enim modo maior pars terrae maiorem tui partem haberet et minorem minor, atque ita te plena essent omnia, ut amplius tui caperet elephanti corpus quam passeris, quo esset isto grandius grandioremque occuparet locum, atque ita frustatim partibus mundi magnis magnas, brevibus breves partes tuas praesentes faceres [...] et feci unam massam grandem distinctam generibus corporum creaturam tuam, sive re uera quae corpora erant, siue quae ipse pro spiritibus finxeram, et eam feci grandem, non quantum erat, quod scire non poteram, sed quantum libuit, undiqueuersum sane finitam, te autem, domine, ex omni parte ambientem et penetrantem eam, sed usquequaque infinitum, tamquam si mare esset ubique et undique per immensa infinitum solum mare et haberet intra se spongiam quamlibet magnam, sed finitam tamen, plena esset utique spongia illa ex omni sua parte ex immenso mari; sic creaturam tuam finitam te infinito ] (conf., VII, 1, 2; 5, 7; MAMMÌ, 2017, pp. 166-170).

12 [...] in iuuentutem [...] qui cogitare aliquid substantiae nisi tale non poteram, quale per hos oculos uideri solet. non te cogitabam, deus, in figura corporis humani, ex quo audire aliquid de sapientia coepi [...] sed quid te aliud cogitarem non occurrebat [...] ut quamuis non forma humani corporis, corporeum tamen aliquid cogitare cogerer per spatia locorum sive infusum mundo siue etiam extra mundum per infinita diffusum, etiam ipsum incorruptibile et inuiolabile et incommutabile, quod corruptibili et uiolabili et commutabili praeponebam [...] ita etiam te [...] grandem per infinita spatia undique cogitabam penetrare totam mundi molem et extra eam quaquauersum per immensa sine termino, ut haberet te terra, haberet caelum, haberent omnia et illa finirentur in te, tu autem nusquam (conf. VII, 1, 1-2; MAMMİ, 2017, pp. 165-166). 
O mesmo aspecto divino é referido no Livro $\mathrm{V}$ das Confissões, logo após o relato do estudo das categorias aos 20 anos de idade, em que Agostinho acrescenta:

Parecia-me muito ignóbil acreditar que tu tivesses a figura da carne humana e fosses delimitado pelos contornos de nossos membros corporais; mas quando queria meditar sobre o meu Deus, não sabia pensar senão numa massa corporal, porque achava que não houvesse nada que não fosse tal - e essa era a causa principal e quase única do meu inevitável erro.

[...] E me parecia mais devoto acreditar que tu, meu Deus, [...] fosses infinito por todos os lados, menos por um, onde se oporia a ti a massa do mal, do que acreditar que tu fosses delimitado por todas as partes pela forma de um corpo humano. E me parecia melhor acreditar que tu não criaste mal algum - porque na minha ignorância este me parecia não só uma substância, mas também um corpo, por não saber pensar tal substância senão como um corpo sutil, mas que, mesmo assim, ocupava um lugar no espaço - que acreditar que derivasse de ti aquilo que julgava ser a substância do mal. E o próprio salvador nosso, teu filho unigênito, eu pensava que fosse algo tirado de tua massa luminosíssima para nossa salvação: em minha vaidade, não acreditava dele senão aquilo de que pudesse me formar uma imagem (conf., $\mathrm{V}, 10$, $19-20){ }^{13}$

O Deus maniqueu não era antropomórfico, não obstante correspondesse a uma massa corporal, tal como tudo que existia. Existir implicava em corporalidade. E, como o mal de fato era observável no mundo, e Deus sumamente bom não poderia ser seu autor, o mal era considerado uma substância de corpo sutil ("massa do mal") da qual todos os males eram oriundos. No entanto, Agostinho posteriormente pondera que fizera mau uso do aprendizado das categorias, empregando-as para defender o erro maniqueu de um Deus material. ${ }^{14}$

\footnotetext{
13 mihi turpe uidebatur credere figuram te habere humanae carnis et membrorum nostrorum liniamentis corporalibus terminari. et quoniam cum de dec meo cogitare uellem, cogitare nisi moles corporum non noueram - neque enim uidebatur mihi esse quidquam, quod tale non esset - ea maxima et prope sola causa erat ineuitabilis erroris mei. [...] infinitum crederem, quamuis ex una, qua tibi moles mali opponebatur, cogerer finitum fateri, quam si ex omnibus partibus in corporis hum ani forma te opinarer finiri. et melius mihi uidebar credere nullum malum te creasse - quod mihi nescienti non solum aliqua substantia, sed etiam corporea uidebatur, quia et mentem cogitare non noueram nisi earn subtile corpus esse, quod tamen per loci spatia diffunderetur - quam credere abs te esse qualem putabam naturam mali. Ipsumque saluatorem nostrum, unigenitum tuum, tamquam de massa lucidissimae molis tuae porrectum ad nostram salutem ita putabam, ut aliud de illo non crederem nisi quod passero uanitate imaginari (conf., V, 10, 19-20; MAMMÌ, 2017, pp. 132133).

${ }^{14}$ Quanto ao aprendizado das artes liberais, que incluíam o ensino das Categorias, Agostinho avalia que "me traziam, mais que proveito, ruína [mihi non ad usum, sed ad perniciem magis ualebat]" (conf., IV, 16, 30; MAMMÌ, 2017, p. 113), por terem sido empenhadas em defender o Deus maniqueu.
} 


\section{A autocrítica}

Agostinho corrigirá esse manejo das categorias. Nas Confissões, já na voz do Bisponarrador (com no mínimo 33 anos de idade). Desta outra perspectiva, ele recusa a espacialidade local divina, buscando conhecer Deus que não mais entendido como uma massa corporal, e sim enquanto uma realidade espiritual. Essa mudança exige um rearranjo na apreciação das categorias, que passarão a se referir a um Deus que simultaneamente convoca e ultrapassa o discurso racional. Nesse sentido, Agostinho mostrará que não bastará defender a inadequação da categoria de lugar para predicar Deus. Em vez disso, Agostinho irá produzir uma torção no discurso, mudando-o conforme seu destinatário e, quanto às categorias, isso promoverá um meneio do discurso categorial para adequar-se a Deus e não o contrário, ou seja, não condicionará o entendimento sobre Deus à coerência e ao alcance do discurso categorial. Tal reviravolta é exemplificada nas Confissões, em um trecho notável, motivo diversas interpretações, ${ }^{15}$ e ao qual gostaríamos de acrescentar uma observação.

No início dessa obra (livro I, capítulo 4), Agostinho interpela seu leitor com um texto difícil, vertiginoso, claramente diferente dos anteriores (pela métrica, pelos termos, pelos oxímoros, pelas contradições). Entre muitas interpretações possíveis, esse texto pode ser lido como uma maneira inusitada de se referir a algumas categorias aristotélicas. De fato, nas Confissões, isso ainda não sobrevém de maneira plenamente sistematizada, como nos Livros V e VI do Sobre a Trindade. Entretanto, é pertinente defender que o texto, que citaremos a seguir, já indica a dificuldade de a linguagem e a compreensão categoriais apreenderem um Deus que transcende o paradigma categorial, mas os convoca a se amoldarem à realidade divina, o que resulta em um texto com contradições significantes. Examinemos tal texto.

O que és, afinal, meu Deus? O que, pergunto, senão o meu Senhor? Quem, de fato, é senhor, além do Senhor? Quem é deus além do nosso Deus? Supremo, ótimo, poderosíssimo, todo-poderosíssimo, misericordiosíssimo e justíssimo, ocultíssimo e evidentíssimo, belíssimo e fortíssimo. Imóvel e inapreensível; imutável, que tudo muda; nunca novo, nunca velho; que tudo renova, mas envelheces os soberbos, $e$ eles não percebem. Sempre ativo, sempre em repouso; que acumula, sem ter carência; que carrega e preenche e protege; que cria e nutre e perfaz; que procura, sem que nada lhe falte. Tu amas e não ardes; és ciumento, mas sem receios; arrependes-te, e não sofres; enfureces-te, e permaneces calmo. Mudas as ações, mas não o propósito; recolhes o que encontras e nunca perdestes; nada te faltando, gozas do que logras; nunca avaro, reclamas juros. Entregamos-te com sobra, para que

\footnotetext{
${ }^{15}$ Como o artigo de Emmanuel Bermon presente neste volume.
} 
fiques em dívida, mas quem possui algo que não seja teu? Dás o que é devido, e nada deves; pagas as dívidas sem nada perder. Mas o que digo, meu Deus, minha vida, minha santa doçura, e o que diz qualquer um, quando fala de ti? E no entanto, ai dos que se calam sobre ti, porque, mesmo falando, são mudos (conf., I, 4, 4). ${ }^{16}$

Agostinho expõe inicialmente tautologias que indicam que nada se predica de Deus adequadamente a não ser que ele é idêntico a si mesmo e nada mais ("O que és, afinal, meu Deus? O que, pergunto, senão o meu Senhor? Quem, de fato, é senhor, além do Senhor? Quem é Deus além do nosso Deus?"). Dado esse pressuposto, Agostinho empenha a linguagem em usos superlativos, indicando o caminho através do qual a atenção humana se direciona para Deus ("supremo, ótimo, poderosíssimo, todo-poderosíssimo”). Tais superlativos, ao serem desenvolvidos, mostram que a linguagem humana, conquanto em sua disposição mais favorável e unicamente orientada ao supremo, é ainda inadequada e move-se entre contradições ("misericordiosíssimo e justíssimo, ocultíssimo e evidentíssimo, belíssimo e fortíssimo"). Na sequência, Agostinho esclarece que essa oscilação da linguagem não respeita ao próprio Deus (“Imóvel e inapreensível”), mas às suas criaturas, estas sim mutáveis (Deus é “imutável, que tudo muda; nunca novo, nunca velho"). Portanto, a ação divina em relação ao homem parece mutável somente em razão da perspectiva daquele que a traduz em palavras. Sendo o homem mutável, seu discurso contraditório é fruto da mutabilidade, da qual o homem não se poderia emancipar. ${ }^{17}$

\footnotetext{
${ }^{16}$ quid es ergo deus meus? quid, rogo, nisi dominus deus? quis enim dominus praeter dominum ? aut quis deus praeter deum i nostrum? summe, optime, potentissime, omnipotentissime, misericordissime et iustissime, secretissirne et praesentissime, pulcherrime et fortissime, stabilis et incomprehensibilis. immutabilis, mutans omnia, nuтquam nouus, numquam uetus, innouans omnia et in uetustatem perducens superbos et nesciunt; semper agens, semper quietus, conligens et non egens, portans et implens et protegens, creans et nutriens et perficiens, quaerens, cum nihil desit tibi. amas nee aestuas, zelas $i$ et securus es, paenitet te et non doles, irasceris et tranquillus es, opera mutas nee mutas consilium; recipis quod inuenis et numquam ami sisti ; numquam inops et gaudes lucris, numquam auarus et usuras exigis. supererogatur tibi, ut debeas, et quis habet quidquam non tuum reddis debita i nulli debens. donas debita nihil perdens. et quid diximus, deus meus, uita mea, dulcedo mea sancta, aut quid dicit aliquis. cum de te dicit? et uae tacentibus de te, quoniam loquaces muti sunt (conf., I, 4, 4; MAMMİ, 2017, pp. 35-36).

${ }^{17} \mathrm{O}$ argumento apresenta-se no parágrafo 3 (imediatamente anterior), em que Agostinho exibe a relatividade da perspectiva humana que, devido à sua mutabilidade essencial, é refém desse filtro e, percebendo tudo como mudança, tende a atribuir seu modo de conhecer àquilo que conhece, até mesmo ao ser imóvel. Esse engano pode ser acusado pela linguagem, quando ela é corrigida pelo pensamento, mesmo que se produza um discurso cujo sentido aparente é contraditório. A contradição, portanto, mostra ao homem que sua linguagem é refém de sua própria mutabilidade e materialidade, não obstante o pensamento consiga corrigi-la ao evidenciar tal oscilação. Esse é um modo de interpretar o seguinte trecho das Confissões: "Então te contêm o céu e a terra, porque tu os preenches? Ou os preenches e ainda sobras, porque não te contêm? E para onde transbordaria o que sobra de ti, uma vez preenchidos o céu e a terra? Ou não é necessário que tu, que conténs todas as coisas, sejas
} 
Com a finalidade de justificar o que acabamos de afirmar, organizarmos o texto supracitado em uma tabela contendo as dez categorias aristotélicas. Eis o resultado:

\section{Quadro I: Análise do uso das categorias em Confissões, I, 4, 4}

\begin{tabular}{|c|c|}
\hline (substantia) & $\begin{array}{l}\text { "O que és, afinal, meu Deus? O que, pergunto, senão o meu Senhor? } \\
\text { Quem, de fato, é senhor, além do Senhor? Quem é deus além do nosso } \\
\text { Deus?" }\end{array}$ \\
\hline $\begin{array}{l}\text { quantidade } \\
\text { (quantitas) }\end{array}$ & $\begin{array}{l}\text { Agostinho detém-se à categoria da quantidade no parágrafo anterior das } \\
\text { Confissões (conf., I, 3, 3), tendo-a considerado como um pressuposto para } \\
\text { a presente exposição. }{ }^{18}\end{array}$ \\
\hline $\begin{array}{l}\text { qualidade } \\
\text { (qualitas) }\end{array}$ & 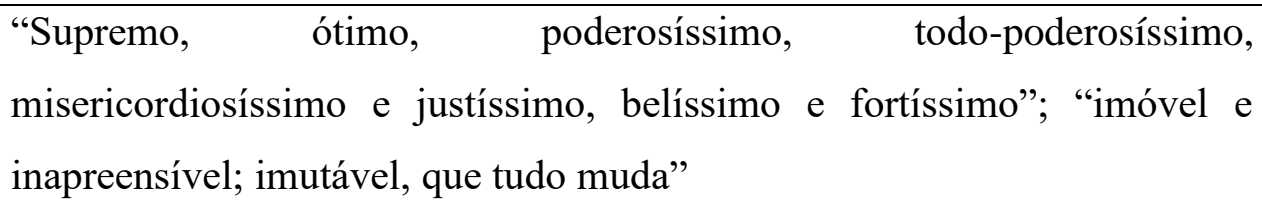 \\
\hline $\begin{array}{l}\text { relação } \\
\text { (relatio) }\end{array}$ & $\begin{array}{l}\text { "O que és, afinal, meu Deus? O que, pergunto, senão o meu Senhor? } \\
\text { Quem, de fato, é senhor, além do Senhor? Quem é deus além do nosso } \\
\text { Deus?"; "que carrega e preenche e protege; que cria e nutre e perfaz" }\end{array}$ \\
\hline $\begin{array}{l}\text { lugar } \\
(u b i)\end{array}$ & "ocultíssimo e evidentíssimo" \\
\hline
\end{tabular}

contido por algo, porque, o que tu preenches, o preenches contendo-o? Com efeito, não são os vasos plenos de ti que te tornam estável: mesmo que eles sejam quebrados, tu não derramarias. E quando derramas sobre nós não desces, mas nos levantas; não te dispersas, mas nos recolhes. Mas, tudo o que preenches o preenches da totalidade de ti. Ou, não podendo te conter inteiro, todos os seres conteriam uma tua parte, e todos a mesma, simultaneamente? Ou cada um singularmente, os maiores uma parte maior, os menores, uma menor? Haveria, portanto, em ti, partes maiores e menores? Ou estás todo em todo lugar, e nada te contém inteiramente?" [capiunt ergone te caelum et terra, quoniam tu imples ea? an imples et restat, quoniam non te capiunt? et quo refundis quidquid impleto caelo et terra restat ex te? an non opus habes, ut quoquam continearis, qui con tines omnia, quoniam quae imples continendo imples? non enim uasa, quae te plena sunt, stabilem te faciunt, quia etsi frangantur non effunderis. et cum effunderis super nos, non tu iaces, sed erigis nos, nee tu dissiparis, sed conligis nos. sed quae imples omnia, te toto imples omnia. an quia non possunt te tatum capere omnia, partem tui capiunt et eandem partem simul omnia capiunt? an singulas singula et maiores maiora, minores minora capiunt? ergo est aliqua pars tua maior, aliqua minor? an ubique totus es et res nulla te totum capit?] (conf., I, 3, 3; MAMMÌ, 2017, pp. 34-35).

${ }^{18}$ Para identificar o novo emprego que Agostinho faz das categorias, pensamos ser suficiente indicar o texto que versa sobre a categoria da quantidade (conf., I, 3, 3). Ademais, o mesmo texto também pode ser entendido como uma reviravolta na utilização das categorias de lugar e de estado. Para citação do trecho mencionado, cf. nota 17. 


\begin{tabular}{|c|c|}
\hline $\begin{array}{l}\text { tempo } \\
\text { (quando) }\end{array}$ & "nunca novo, nunca velho"19 \\
\hline $\begin{array}{l}\text { estado } \\
(\text { situs })\end{array}$ & "ocultíssimo e evidentíssimo" \\
\hline $\begin{array}{l}\text { hábito } \\
\text { (habere) }\end{array}$ & $\begin{array}{l}\text { "nada te faltando, gozas do que logras; nunca avaro, reclamas juros. } \\
\text { Entregamos-te com sobra, para que fiques em dívida, mas quem possui } \\
\text { algo que não seja teu? Dás o que é devido, e nada deves; pagas as dívidas } \\
\text { sem nada perder"; "que acumula, sem ter carência" }\end{array}$ \\
\hline $\begin{array}{l}\text { ação e paixão } \\
(\text { actio / passio })\end{array}$ & $\begin{array}{l}\text { "imutável, que tudo muda; que tudo renova, mas envelheces os soberbos, } \\
\text { e eles não percebem"; "sempre ativo, sempre em repouso"; "mudas as } \\
\text { ações, mas não o propósito; recolhes o que encontras e nunca perdestes; } \\
\text { nada te faltando, gozas do que logras; nunca avaro, reclamas juros"; "tu } \\
\text { amas e não ardes; és ciumento, mas sem receios; arrependes-te e não } \\
\text { sofres; enfureces-te, e permaneces calmo." }\end{array}$ \\
\hline
\end{tabular}

Seriam as contradições categóricas da linguagem a proposta de um outro uso da predicação? Segundo nossa interpretação, parece ser exatamente isso que Agostinho exemplifica no trecho examinado: as palavras e frases combinam-se e se contrapõem, acusando a limitação de algumas das categorias aristotélicas ao tentarem produzir um discurso sobre Deus. A contradição diz respeito ao discurso (palavra e pensamento), não obstante as palavras indiquem a existência de algo por elas inapreensível ou, em outros termos, de um ser que excede o esquema categorial (da linguagem e da realidade). No texto, as categorias produzem rasteiras nas categorias, e o discurso anticategórico (porque contraditório) serve não só para denunciar o alcance de algumas categorias, mas também exibe uma incoerência de face, que recobra sua unidade não em si, mas ao render-se à existência de algo impredicável, ou "predicável” pelo abuso das mesmas categorias.

\footnotetext{
${ }^{19}$ O livro XI das Confissões mostra as dificuldades da linguagem e do pensamento categorial (linguagem e pensamento podem ser agrupados no discurso categorial) diante de um Deus que é eterno (sem categoria temporal).
} 


\section{BIBLIOGRAFIA}

\section{Obras de Agostinho em latim}

AURELII AUGUSTINI. Confessionum libri XIII. Ed. L. Verheijen. In: SANTI AUGUSTINI OPERA, CORPUS CHRISTIANORUM, Series Latina 27. Brépols, Turnhout, 1990, editio altera.

Contra Cresconium grammaticum Donatistam libri quatuor. In: S. Aurelii Augustini Opera Omnia, editio latina, Patrologia Latina 43. Disponível em: http://www.augustinus.it/latino/contro cresconio/index2.htm. Acesso em em 12 de out. 2018.

. Contra Iulianum opus imperfectum libri sex. In: S. Aurelii Augustini Opera Omnia, editio latina, Patrologia Latina 45. Disponível em: http://www.augustinus.it/latino/incompiuta giuliano/index2.htm. Acesso em em 12 de out. 2018.

De dialectica. In: S. Aurelii Augustini Opera Omnia, editio latina, Patrologia Latina 32. Disponível em: http://www.augustinus.it/latino/dialettica/index2.htm. Acesso em em 12 de out. 2018.

De Genesi contra Manichaeos libri duo. In: S. Aurelii Augustini Opera Omnia, editio latina, Patrologia Latina 34. Disponível em: http://www.augustinus.it/latino/genesi_dcm/index2.htm. Acesso em em 12 de out. 2018.

De immortalitate animae liber unus. In: S. Aurelii Augustini Opera Omnia, editio latina, Patrologia Latina 32. Disponível em: http://www.augustinus.it/latino/immortalita_anima/index2.htm. Acesso em em $12 \mathrm{de}$ out. 2018.

De Trinitate Livri XV. Ed. W. J. Mountain; Fr. Glorie. In: SANTI AUGUSTINI OPERA, CORPUS CHRISTIANORUM, Series Latina 50. Brépols, Turnhout, 1968.

Obras de Agostinho em línguas modernas

AGOSTINHO. A Trindade: Edição bilíngue português-latim. Trad. Arnaldo do Espírito Santo et al. Prior Velho: Paulinas , 2007. $1201 \mathrm{p}$.

. Confissões. Trad. Lorenzo Mammì. São Paulo: Penguin Classics Companhia das Letras, 2017. 410 p.

O’DONNELL, J. J. The Confessions of Augustine: An electronic edition. Disponível em: http://www.stoa.org/hippo/. Acesso em 12 de out. 2018.

\section{Bibliografia secundária}

AYOUB, C. N. A. Agostinho e as categorias de Aristóteles (Sobre a Trindade V e VI). In: SILVA, M. A. O. (Org.). Linguagem e Verdade na Filosofia Medieval. Salvador: Editora Quarteto, 2013. p. 53-70.

. Augustinus homo dialecticus: a defesa da dialética em "Contra Crescônio, gramático e donatista".

Revista Analytica. 2019 (no prelo). 
BÖMER, F. Der lateinische Neuplatonismus und Claudianus Marmetus in Sprache und Philosophie. In: Klassisch-Philologische Studien, 7, Leipzig 1936, p. 91-95.

BROWN, P. Santo Agostinho: uma biografia. Trad. Vera Ribeiro. 8. ed. Rio de Janeiro: Record, 2015. 669 p.

COURCELLE, P. Recherches sur les Confessions de saint Augustin. 2. ed. Paris: De Boccard, 1968. 615 p.

DE GHELLINCK, J. Quelques appréciations de la dialectique et d'aristote durant les conflits trinitaires du IVe siècle. Revue d'Histoire Ecclesiastique 25, p. 5-42. 1930.

DU ROY, O. L'intelligence de la foi en la trinité selon saint Augustin: genèse de sa théologie trinitaire jusqu'en 391. Paris: Études Augustiniennes, 1966.

PALUELLO, L. M. The Text of the Categoriae: The Latin Tradition. The Classical Quarterly 39 (vols. 3-4), pp. 63-74, 1945.

MARROU, H.-I. Saint Augustin et la fin de la culture antique. Paris: De Boccard, 1958. 713 p.

PEPIN, J. Saint Augustin et la dialectique. Villanova: Villanova University Press, 1976. 277 p.

MANDOUZE, A. Saint Augustin: L'aventure du raison et de la grâce. Paris: Études augustiniennes, 1968. 797 p. 